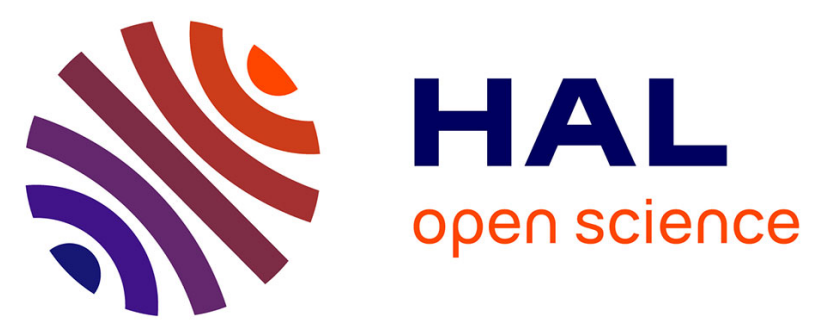

\title{
Effect of the processing conditions on the viscoelastic properties of a high-RAP recycled asphalt mixture: micromechanical and experimental approaches
}

Rabeb Cherif, Anissa Eddhahak, Thomas Gabet, Farhat Hammoum, Jamel Neji

\section{To cite this version:}

Rabeb Cherif, Anissa Eddhahak, Thomas Gabet, Farhat Hammoum, Jamel Neji. Effect of the processing conditions on the viscoelastic properties of a high-RAP recycled asphalt mixture: micromechanical and experimental approaches. International Journal of Pavement Engineering, 2019, pp.1-10. 10.1080/10298436.2019.1640363 . hal-02547523

\section{HAL Id: hal-02547523 \\ https://hal.science/hal-02547523}

Submitted on 20 Apr 2020

HAL is a multi-disciplinary open access archive for the deposit and dissemination of scientific research documents, whether they are published or not. The documents may come from teaching and research institutions in France or abroad, or from public or private research centers.
L'archive ouverte pluridisciplinaire HAL, est destinée au dépôt et à la diffusion de documents scientifiques de niveau recherche, publiés ou non, émanant des établissements d'enseignement et de recherche français ou étrangers, des laboratoires publics ou privés. 


\title{
Effect of the processing conditions on the viscoelastic properties of a high-RAP recycled asphalt mixture: micromechanical and experimental approaches
}

\author{
Rabeb Cherif ${ }^{\mathrm{a}}$, Anissa Eddhahak ${ }^{\mathrm{b}}$, Thomas Gabet ${ }^{\mathrm{c}}$, Farhat Hammoum ${ }^{\mathrm{c}}$ and Jamel Neji ${ }^{\mathrm{a}}$ \\ a LRMOED, National Engineering School of Tunis, Tunis El Manar University, Tunis, Tunisia; ${ }^{\mathrm{b}} \mathrm{PIMM}, \mathrm{CNRS}$ UMR 8006, Arts et Métiers ParisTech, Paris, \\ France; ${ }^{\mathrm{I} I F S T T A R, ~ M A S T}$, MIT, Bouguenais Cedex, France
}

\begin{abstract}
With the depletion of the virgin aggregates, many efforts have been oriented towards the recycling of the reclaimed asphalt pavement (RAP). However, quality control of the recycled product is required during the manufacture process. This research deals with the use of high-content RAP recycled asphalt mixture composed of $70 \%$ RAP based on experimental and micromechanical approaches. For the experimental part, a "Good" and a "Bad" blended mixture were manufactured in laboratory. Then, rheological measurements of the complex modulus of the different binders and mixtures were carried out. The micromechanical work is based on the generalised self-consistent scheme (GSCS) which was used to predict the mechanical properties of the recycled mixture. This approach aims to homogenize the heterogeneous material by taking into account both the intergranular porosity and the possible interactions between phases. The confrontation of the micromechanical model with the experimental results showed good agreements between measured data and predicted values of the complex modulus of the recycled asphalt. Moreover, it was highlighted from the experimental results that the blending process of the recycled mixture has a great influence on the viscoelastic properties of the recycled mixture. This result was also validated by the GSCS-based approach.
\end{abstract}

\section{Nomenclature}

$\mu \quad$ shear modulus

$\varepsilon \quad$ the micro-strain field

$\Delta \mathrm{E} \quad$ the difference between the measured and calculated modulus

$\Delta \mathrm{C} \quad$ the difference between the experimental void content measured and the reference one

$A_{i} \quad$ the strain localisation 4th-order tensor associated to the phase $\mathrm{i}$

$A_{i}, B_{i}, F_{i} \quad$ constants defined in the appendix A.

$a_{\mathrm{T}} \quad$ the shift factor for temperature $\mathrm{T}$

$\mathrm{BC}$ the binder content

$C_{1}, C_{2} \quad$ positive constants that depend on the material and the reference temperature;

$C$ the stiffness 4th-order tensor

$E_{0} \quad$ uniform strain condition at infinity

$E^{\star} \quad$ complex modulus of stiffness

$f_{i} \quad$ the volume fraction associated to the phase $\mathrm{i}$

$G^{*} \quad$ shear complex modulus

I the identity 4 th-order tensor

$k_{i} \quad$ bulk modulus to the phase i

$k^{\text {hom }} \quad$ the homogenised bulk modulus

$L \quad$ the strain localisation tensor

$L_{i} \quad$ the strain localisation tensor associated to the phase i

$T$ temperature

$T_{r} \quad$ the reference temperature.

$x \quad$ micro-coordinate of a point of the RVE

\section{Introduction}

Nowadays, with the increase of the material cost and the depletion of natural resources, RAP has become the most common resource for the production of new asphalt mixtures (Vanelstraete et al. 2004, Navaro 2011, Bhusal and Wen 2013, Islam et al. 2014; Sabahfer and Hossain 2015, Kaseer et al. 2018, Saha and Mondala 2018, Zaumanis et al. 2019). In fact, the reuse of waste materials is considered as an economic and environment-friendly solution to minimise the need for natural resources and to reduce the energy consumption (Little et al. 1981, Button et al. 1994). In recent years, many research works have been focused on the use of high proportions of RAP for the production of recycled asphalt mixtures, but this tendency is sometimes constrained by the lack of information and experience feedback on the sustainability of this technology and the end properties of the recycled product. In particular, the rigidity of the recycled asphalt mixture commonly determined by the complex modulus test is one of the fundamental properties to check the viscoelastic performance of the recycled mixture. However, the laboratory measurement of complex modulus is a time-consuming task, which requires carrying experiments at many temperatures and frequencies as well as trained technicians to perform it.

In this context, many researchers have been oriented to the determination of the viscoelastic properties, and notably the complex modulus, of asphalt mixture by using predictive approaches. Accordingly, empirical and analytical models have been developed for this purpose. Some of them used information derived from the mix design properties of the blend, and the others were based on the rheological properties of the bituminous binder, in order to predict the complex 
modulus of the asphalt mixture (Shell Bitumens 1991, Franken and Vanelstraete 1995, Di benedetto and Des Croix 1996, Huet 1999, Bazzaz et al. 2018). Several models have shown some limitations at specific frequency and temperature ranges $(\mathrm{Xu}$ and Solaimanian 2009) and others often require complementary experimental tests (Dibenedetto et al. 2004). For these reasons, innovative approaches based on the rational mechanics have been adopted to predict the viscoelastic properties of the asphalt mixture. Micromechanics, for instance, aims to provide reliable deductive tools for the prediction of the effective properties of the heterogeneous material based on the knowledge of the mechanical properties and the volume fractions of the different phases. Since 1990, these models have been used to predict the effective viscoelastic behaviour of asphalt mastic and mixtures (Buttlar and Roque 1996, Buttlar et al. 1999, Shashidhar and Shenoy 2002, Kim and Little 2004, Lachihab 2004, Yin et al. 2008, Aigner et al. 2012, Underwood and Kim 2014, Alam and Hammoum 2015, Fakhari Tehrani et al. 2016, Riccardi et al. 2017). More recently, a micromechanical model based on the generalised self-consistent scheme (GSCS) (Eddhahak-Ouni et al. 2015) was developed. This model aims to predict the behaviour of high-RAP content recycled asphalt mixtures by taking into account the asphalt microstructure in order to investigate the effect of the homogeneity level between the virgin and the RAP binders on the viscoelastic properties of the heterogenous material. The model was validated in the elastic case (Eddhahak-Ouni et al. 2015) and needs to be checked in the viscoelastic one.

In this context, and in order to predict the behaviour of high-RAP content recycled asphalt mixtures, this work is involved in a larger research programme and aims to investigate the effect of the homogeneity level between the virgin and the RAP binders on the viscoelastic properties of the heterogeneous material based on an experimental and micromechanical approaches.

Note that other researchers have also focused on the influence of the manufacture method on the viscoelastic properties of the asphalt concrete. For instance, the works of Navaro (2011) and Daniel et al. (2018) proved that the processing conditions affect tremendously the properties of the recycled asphalt mixture and they concluded that this could be due to the bad mixing of the virgin and the RAP binders.

Therefore, the objectives of the present work are threefold:

(1) To determine experimentally the complex modulus of high-RAP content recycled mixtures with different processing conditions (good and bad blending)
(2) To compare the experimental results of complex modulus with the ones obtained by the suggested micromechanical model

(3) To analyse the effect of blending level on the viscoelastic behaviour of high-RAP content rate recycled asphalt mixture.

\section{Theoretical background}

In this section, the development basics of the micromechanical model used in this study are briefly introduced. For additional details about the model development, the readers could consult the research work of Eddhahak-Ouni et al. (2015).

Next, for the modelling part, let assume that an asphalt mixture containing RAP is composed of aggregates coated with aged binder (RAP), virgin aggregates, virgin binder and porosity (Figure 1). According to the blending level, one can imagine two microstructure configurations for the recycled asphalt mixture:

(1) The 'well-blended' case (Mix 1) for which one assumes that the virgin binder and the RAP-binder are well blended together such as a single homogeneous binder layer surrounds the aggregates. This is called the 'well-blended' configuration (Figure 2(a)).

(2) The 'bad-blended' case (Mix 2) for which the virgin and RAP binders are not sufficiently blended, so that one can imagine two binder layers around the aggregates corresponding to the RAP (close to the aggregate) and virgin binders. This is called the 'bad-blended' configuration (Figure 2(b)).

Based on these considerations, a micromechanical model was developed by the authors based on the generalised self-consistent scheme (GSCS). The latter is widely used in the literature to describe the case of a multi-layered composite inclusion immersed into an infinite matrix of the equivalent homogeneous material (EHM).

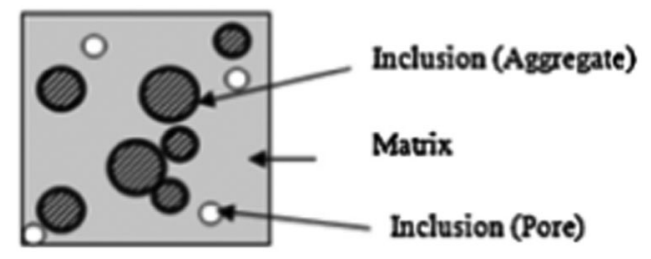

Figure 1. Schematic modelling of the asphaltic concrete (Eddhahak-Ouni et al., 2015).

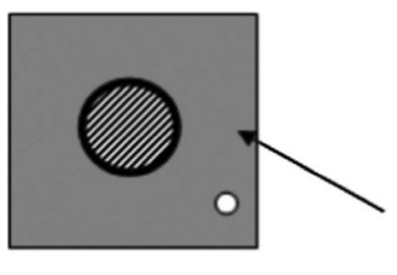

a)

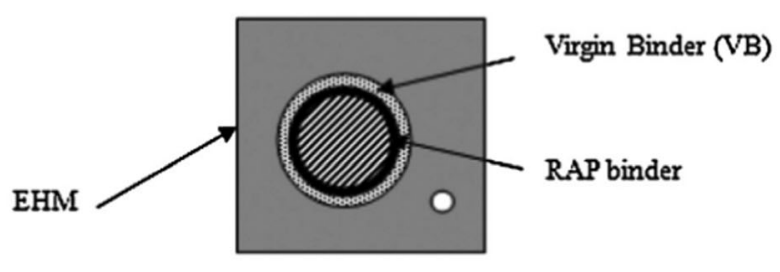

b)

Figure 2. GSCS representations of recycled asphaltic concretes: (a) 'well-blended' case (b) 'bad-blended' case (Eddhahak-Ouni et al., 2015). 
In the present case, a 'non-ordinary' representative volume element (RVE) is considered here. It is composed of two types of spherical inclusions (aggregates and porosity) embedded in an equivalent homogeneous infinite medium subjected to uniform strain condition $E_{0}$ at infinity. Each phase is characterised by a bulk modulus $\mathrm{k}_{\mathrm{i}}$, a shear modulus $\mu_{\mathrm{i}}$ and a volume fraction $\mathrm{f}_{\mathrm{i}}$.

The global problem corresponding to the 'non-ordinary' RVE can be solved by considering simultaneously two secondary classical problems named SP1 and SP2 (Figure 3) with one single inclusion for each one, associated respectively with the rigid inclusion (aggregate) and the 'weak' inclusion (porosity), subjected to the same auxiliary deformation $\mathrm{E}_{0}$ at infinity. Consequently, the generalised self-consistent scheme can be used for each RVE with the single composite inclusion.

The effective stiffness of the heterogeneous material can be written as follow:

$$
C^{\text {hom }}=\langle C: A\rangle=\sum_{i} f_{i} C_{i}:\left\langle A_{i}\right\rangle
$$

Where $C^{\text {hom }}$ is the effective stiffness 4 th-order tensor, $C_{i}$ is the local stiffness 4th-order tensor, $A_{i}$ is the strain localisation 4thorder tensor phase $i$ associated to the secondary problem and $f_{i}$ is the volume fraction associated to the phase $\mathrm{i}$.

In the case of the global problem, the average strain localisation tensor denoted $L$ relates the micro-strain field $\varepsilon$ of each point of micro-coordinate $x$ of the RVE to the macro-strain field $E$ applied at infinity:

$$
\varepsilon_{i}(x)=\left\langle L_{i}(x)\right\rangle: E
$$

The strain localisation tensor $\mathrm{L}$ of the global problem is related to the secondary problems as follow:

$$
\left\langle L_{i}\right\rangle=\left\langle A_{i}\right\rangle:\left(\sum_{i} f_{i}\left\langle A_{i}\right\rangle\right)^{-1}
$$

On the other hand, in the linear and isotropic case, the stiffness tensor is given by:

$$
C=3 k I^{v o l}+2 \mu I^{d e v}
$$

Where $I^{v o l}$ and $I^{d e v}$ are respectively the spherical and deviatory 4th-order operators.

By considering a displacement approach with boundary displacements conditions, one can determine the average strain in each phase under both uniform (hydrostatic pressure) and deviatoric (shear force) strain conditions as:

$$
\left\{\begin{aligned}
\left\langle\varepsilon_{i}^{S p h}\right\rangle & =\frac{\mathbf{F}_{\mathbf{i}}}{\mathbf{F}_{\mathbf{n}+1}} \cdot I \cdot E_{0}=A_{i}^{S p h} \cdot E_{0} \\
\left\langle\varepsilon_{i}^{d e v}\right\rangle & =\frac{1}{A_{n+1}} \cdot\left(\mathbf{A}_{\mathbf{i}}-\frac{21}{5} \cdot \frac{R_{i}^{5}-R_{i-1}^{5}}{\left(1-2 v_{i}\right)\left(R_{i}^{3}-R_{i-1}^{3}\right)} \cdot \mathbf{B}_{\mathbf{i}}\right) I \cdot E_{0} \\
& =A_{i}^{d e v} \cdot E_{0}
\end{aligned}\right.
$$

Where $R_{i}$ denotes the radius of the phase i, the coefficients $\mathbf{A}_{\mathbf{i}}$, $\mathbf{B}_{\mathbf{i}}$ and $\mathbf{F}_{\mathbf{i}}$ are constants fully identified in the work Herve and Zaoui (1993) and $I$ is the identity 4th-order tensor.

Once the localisation tensor of the global problem is determined using Eq. (3), the homogenised bulk and the homogenised shear, respectively $k^{\text {hom }}$ and $\mu^{\text {hom }}$, can be deduced:

$$
\begin{aligned}
k^{\mathrm{hom}}= & \left(f_{a} k_{a} \mathrm{~A}_{a}^{s p h}+f_{m} k_{m} \mathrm{~A}_{m}^{s p h}+f_{p} k_{p} \mathrm{~A}_{p}^{s p h}\right): \\
& \left(f_{a} \mathrm{~A}_{a}^{s p h}+f_{m} \mathrm{~A}_{m}^{s p h}+f_{p} \mathrm{~A}_{p}^{s p h}\right)^{-1} \\
\mu^{\text {hom }}= & \left(f_{a} \mu_{a} \mathrm{~A}_{a}^{d e v}+f_{m} \mu_{m} \mathrm{~A}_{m}^{d e v}+f_{p} \mu_{p} \mathrm{~A}_{p}^{d e v}\right): \\
& \left(f_{a} \mathrm{~A}_{a}^{d e v}+f_{m} \mathrm{~A}_{m}^{d e v}+f_{p} \mathrm{~A}_{p}^{d e v}\right)^{-1}
\end{aligned}
$$

Once the homogenised bulk and shear moduli are determined from the equation system (6) one can easily deduce the complex modulus ' $E$ hom' which will be used in this work to compare the experimental results with the numerical one.

\section{Materials and methodology}

\subsection{Materials description}

The aggregates used in the recycled asphalt concretes are composed of $70 \%$ of RAP and 30\% of new aggregate. The RAP binder is extracted and recovered according to European Standards NF EN 12697-3. The binder content was found equal to $4.3 \%$. The recycled asphalt mixture is a $30 / 50$

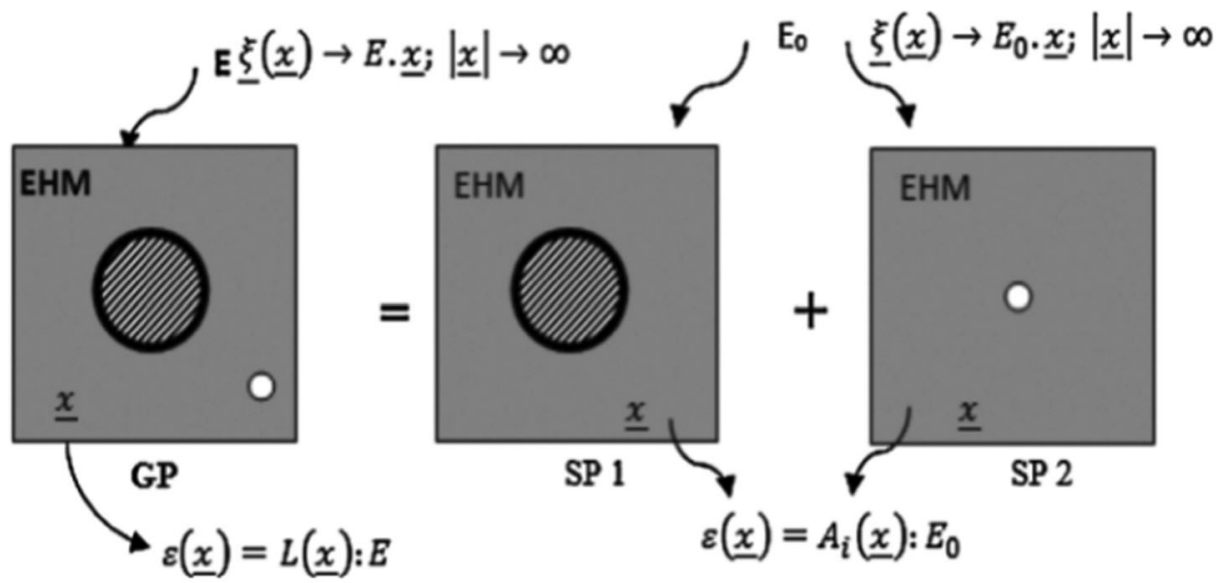

Figure 3. Global problem of homogenisation « GP » (Eddhahak-Ouni et al., 2015). 


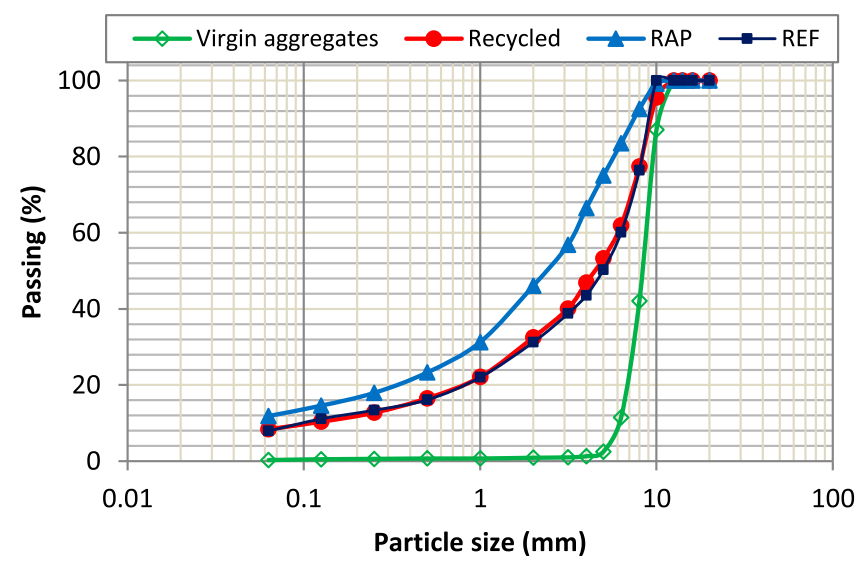

Figure 4. Particle size distributions of used aggregates.

penetration grade bitumen, whereas the virgin and the RAP bitumens are 70/100 and 10/20 penetration grades respectively.

The recomposition of the recycled asphalt mixtures were performed such as to be as close as possible to a conventional dense asphaltic concrete $0 / 10$ composition with $2.5 \%$ air void content denoted here by (BBSG). Accordingly, a 30/50 penetration grade bitumen and a binder content of 5.5\% were used for the final-recycled mixtures.

Figure 4 shows the particle size distributions of virgin aggregates, RAP aggregates as well as the recycled asphalt in comparison with the reference (REF) asphalt mixture. It can be noted that the recycled mixture and the reference asphalt have the same particle size distributions.

\subsection{Laboratory testing procedure}

Three asphalts mixtures were prepared in this study: two recycled mixes with $70 \%$ of RAP content prepared using two different processing conditions and a typical BBSG mix that served as control (labelled as REF). The mixing conditions (temperature and time parameters) were controlled in order to obtain a 'well-blended' asphalt mixture (denoted 'Mix 1') and a 'bad-blended' one (denoted 'Mix 2').

Based on the past studies of the co-authors (Navaro 2011, Eddhahak-Ouni et al. 2012), the processing parameters considered for this study are summarised in Table 1.

\subsection{Complex modulus measurements}

The complex modulus of the binders were performed within the linear viscoelastic regime using a Rheometer Metravib ${ }^{\circ}$

Table 1. Operating manufacture conditions.

\begin{tabular}{lccc}
\hline Mixtures & $\begin{array}{c}\text { Mix } 1 \text { (Well- } \\
\text { blended) }\end{array}$ & $\begin{array}{c}\text { Mix 2 (Bad- } \\
\text { blended) }\end{array}$ & REF \\
\hline Asphalt mixture formulation & \multicolumn{3}{c}{ BBSG $\mathbf{0 / 1 0}$} \\
RAP content & $70 \%$ & $70 \%$ & $0 \%$ \\
Virgin Binder Content (BC) & $2.5 \%$ & $2.5 \%$ & $5.5 \%$ \\
RAP temperature, ${ }^{\circ} \mathrm{C}$ & 130 & 110 & \\
Virgin aggregate temperature, & 230 & 105 & 160 \\
${ }^{\circ} \mathrm{C}$ & & & \\
Mixing temperature, ${ }^{\circ} \mathrm{C}$ & 160 & 110 & 160 \\
Mixing time (s) & 240 & 40 & 120 \\
\hline
\end{tabular}

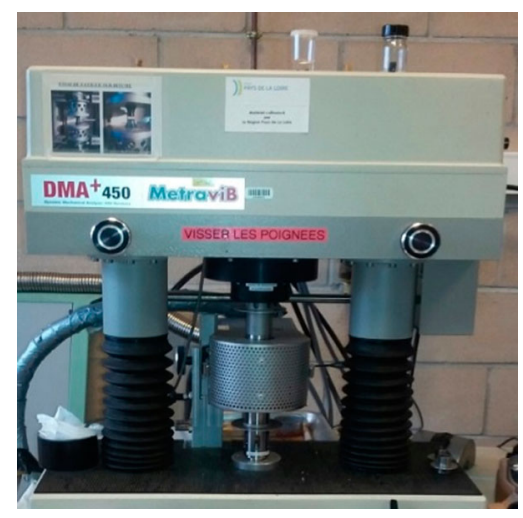

Figure 5. Metravib equipment for the binder testing.

device (XP T66-065) at the frequency range $1-80 \mathrm{~Hz}$ with temperature varying from $-10^{\circ} \mathrm{C}$ to $60^{\circ} \mathrm{C}$ (Figure 5). The complex modulus $\left(E^{*}\right)$ was obtained in traction-compression configuration from $-10^{\circ} \mathrm{C}$ to $20^{\circ} \mathrm{C}$. Experiments were carried on cylindrical samples $($ diameter $=10 \mathrm{~mm}$; height $=22 \mathrm{~mm}$ ). For the temperature range $20^{\circ} \mathrm{C}$ to $60^{\circ} \mathrm{C}$, the complex shear modulus $\left(G^{*}\right)$ was obtained with annular shearing geometry and experiments were conducted on hollow cylindrical samples (inside diameter $=8 \mathrm{~mm}$, outside diameter $=10 \mathrm{~mm}$, height $=$ $20 \mathrm{~mm})$. For this range of temperature $\left(20^{\circ} \mathrm{C}\right.$ to $\left.60^{\circ} \mathrm{C}\right)$, the conversion from $G^{*}$ to $E^{*}$ was made by assuming a Poisson's ratio of 0.5 . This test was performed on four types of bitumen: the RAP bitumen, the virgin bitumen, the blend of RAP and virgin bitumen and the reference bitumen.

The measurements of the complex modulus of asphaltic concretes were performed at the frequency range $3-40 \mathrm{~Hz}$ with temperatures varying between $-10^{\circ} \mathrm{C}$ and $30^{\circ} \mathrm{C}$ in order to build a complete master curve (European Standard NF EN 12697-26) (Figure 6). For each test, three prismatic samples $40 \times 40 \times 120 \mathrm{~mm}^{3}$ were tested (Figure 7). The French Gyratory Shear Press (Figure 8) was used according to European Standards NF EN 12697-31 in order to have a similar air void content (Table 2) for the mixtures. The measurements were performed on three types of asphalts mixtures: the recycled 'well-blended' asphalt (Mix 1), the recycled 'bad-blended'

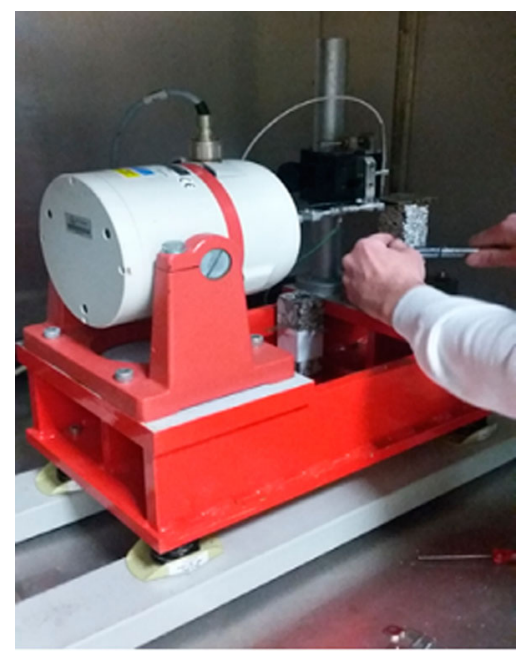

Figure 6. Testing device for complex modulus measurements of asphalt mixes. 


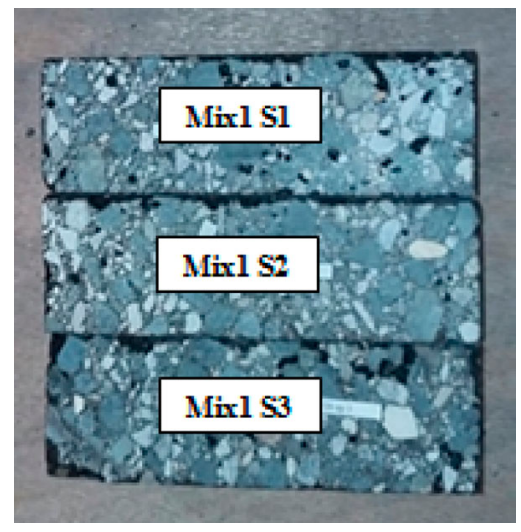

Figure 7. Prismatic samples used for the complex modulus test (Case of 'Mix 1' well-blend asphalt).

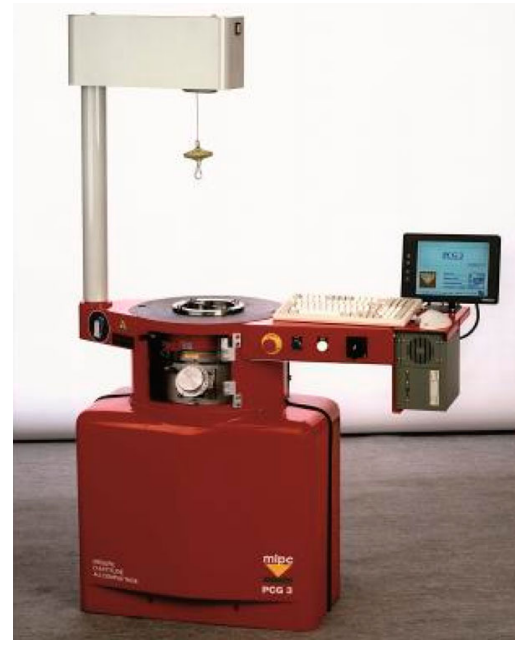

Figure 8. The French Gyratory Shear Press.

Table 2. Air void content of recycled asphalt mixtures.

\begin{tabular}{lccc}
\hline Mixture & Mix 1 (Well-blended) & Mix 2 (Bad-blended) & REF \\
\hline Air void content, \% & 2.6 & 2.1 & 3.2 \\
& 3.2 & 2.8 & 3.1 \\
& 2.9 & 2.3 & 2.9 \\
\hline
\end{tabular}

asphalt (Mix 2) and the reference asphalt (REF). For each asphalt mixture, three specimens were manufactured and tested.

\section{Results and discussion}

This section presents the results of complex modulus tests of the binders and the asphalt mixtures. These results will be used to test the effect of the processing conditions on the viscoelastic properties of a high-RAP content recycled asphalt mixture, on the one hand, and to validate the micromechanical model for the viscoelastic behaviour on the other one.

\subsection{Complex modulus tests}

The results of the experimental measurements of the complex modulus of both binders and asphalt mixtures are presented in this section. The master curves are plotted from the experimental results using the time-temperature superposition principle. The master curve presented at the reference temperature of $15^{\circ} \mathrm{C}$ was obtained by shifting horizontally the dynamic modulus curves at various temperatures along the frequency axis using the following equation:

$$
E^{*}(\omega, T)=E^{*}\left(\omega \cdot a_{T}, T_{r}\right)
$$

Where $a_{T}$ denotes the shift factor of the isothermal $T$ with regards to the reference temperature $T_{r}$. This factor can be described by the WLF relationship (Williams et al. 1955):

$$
\log a_{T}=\frac{-C_{1} \times\left(T-T_{r}\right)}{C_{2}+\left(T-T_{r}\right)}
$$

Where $C_{1}$ and $C_{2}$ are positive constants that depend on the material and the reference temperature.

The curves plotted in Figure 9 show that the different binders exhibit similar tendencies characterised by an increase of the complex moduli with the increase of the solicitation frequency. It can also be noticed that unlike the virgin binder, which represents the softest bitumen, the RAP binder exhibits here the highest complex modulus since it was hardest due to the thermo-mechanical history it has undergone, which has caused its aging. As expected, the blend curve is positioned between the curves of RAP and virgin bitumens.

The results of the complex modulus tests of asphalt mixtures are presented in Figure 10 in terms of master curves given at the reference temperature of $15^{\circ} \mathrm{C}$. One can notice that the behaviour of the two recycled asphalt mixtures are close to the one of the reference asphalt mixture, which shows that despite the high rate of the RAP in the mixture, the properties of the asphalt concrete are still similar to the reference one. One can, however, notice a slight increase of the complex modulus of 'Mix 1' in comparison with 'Mix 2' notably at frequencies lower than $100 \mathrm{~Hz}$. The maximal error recorded between the two experimental master curves was estimated to $16 \%$ obtained at the frequency $0.04 \mathrm{~Hz}$.

The reference bituminous concrete seems closer to the 'wellblended' asphalt (Mix 1) notably in the frequency range $0.03-$ $200 \mathrm{~Hz}$, whereas, for higher frequencies, the three curves are nearly superimposed which let deduce a similar behaviour of

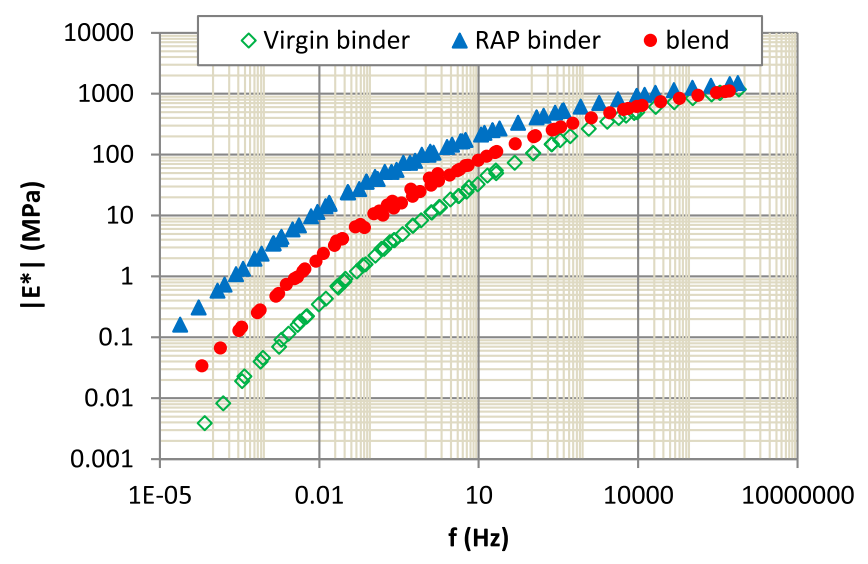

Figure 9. Master curves of tested binders at $15^{\circ} \mathrm{C}$. 


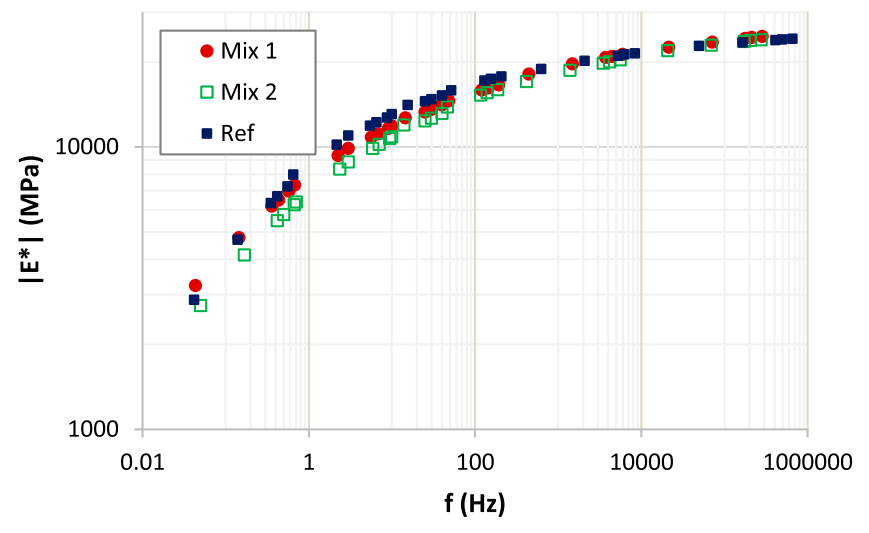

Figure 10. Master curves of asphalt mixtures at $15^{\circ} \mathrm{C}$ (Ref: reference asphalt mixture; Mix 1: well-blended asphalt mixture; Mix 2: bad-blended asphalt mixture).

the recycled mixtures and the reference asphalt for short solicitation times.

Note that the results of the complex moduli of mixtures correspond to the average values computed on the three specimens considered for each type of mixture. Since the void contents in 'Mix 1', 'Mix 2' and 'REF' are slightly different, one suggests that the experimental complex moduli for the different mixtures will be corrected, in order to refine the comparison of the mixtures. For this purpose, the relation of Moutier was used (Eq. 7) (Moutier 1991). This equation allows the estimation of the complex modulus for a given compaction degree of $2.5 \%$ taken as a reference, in function of the experimental complex modulus obtained from samples with different compaction degrees.

$$
\Delta \mathrm{E}=\Delta \mathrm{C} \times\left(-0.078+\frac{0.63}{\mathrm{BC}}\right) \times 10000
$$

Where:

- $\Delta \mathrm{E}$ : The difference between the measured and calculated modulus

- $\Delta \mathrm{C}$ : The difference between the experimentally measured void content and the reference one

- BC: The binder content

Table 3 presents the corrected complex modulus at $15^{\circ} \mathrm{C}$ and $10 \mathrm{~Hz}$ in comparison with the experimental ones.

It can be shown from the data recorded in Table 3 that the difference between the complex modulus of 'Mix 1' and 'Mix 2' with the same air void content is equal to $10 \%$ estimated at $15^{\circ}$ $\mathrm{C}$ and $10 \mathrm{~Hz}$. When compared to the reference case, one can note that the 'well-blended' asphalt (Mix 1) underestimates

Table 3. Experimental and corrected $\left|E^{*}\right|$ at $15^{\circ} \mathrm{C}$ and $10 \mathrm{~Hz}$.

\begin{tabular}{|c|c|c|}
\hline Mixtures & $\left|E^{*}\right|, \mathrm{MPa}$ & Corrected $\left|E^{*}\right|, \mathrm{MPa}$ \\
\hline $\begin{array}{l}\text { Mix } 1 \\
\text { (Well-blended) }\end{array}$ & 11830 & 11990 \\
\hline $\begin{array}{l}\text { Mix } 2 \\
\quad \text { (Bad-blended) }\end{array}$ & 10840 & 10800 \\
\hline REF & 13040 & 13260 \\
\hline Error Mix1/REF, \% & \multicolumn{2}{|c|}{9} \\
\hline Error Mix2/REF, \% & \multicolumn{2}{|c|}{18} \\
\hline Error Mix1/Mix2, \% & \multicolumn{2}{|c|}{10} \\
\hline
\end{tabular}

the rigidity of the asphalt of about $9 \%$. This loss of rigidity is more pronounced in the case of 'bad-blended' (Mix 2) with $18 \%$ in comparison with the reference case. Besides, it can be seen that, although they have the same formulation, the recycled 'bad-blended' asphalt mixture (Mix 2) has a complex modulus lower than the 'well-blended' one (Mix 1). This result highlights the crucial role of the processing conditions and thereby the microstructure in the control of the mechanical behaviour of the recycled asphalts mixtures.

\subsection{Model validation}

This section presents the outcome of the comparison between the experimental and the predicted results of the recycled asphalt mixtures with $70 \%$ of RAP content to check the validity of the suggested GSCS-based micromechanical model presented in Section 2.

Figure 11 shows the comparison of the complex modulus estimated experimentally and by the micromechanical model for the 'well-blended' asphalt (Mix 1) at $T=15^{\circ} \mathrm{C}$. It can be seen that the micromechanical model overestimates the complex modulus at low frequencies (high temperatures). This may be due to the fact that the model relies on the continuity of stress and strain fields across the interface, but in the bituminous mixes at high temperatures (low frequencies), the interfaces may not remain perfect and the interactions between the different phases become weak, resulting thereby in a discontinuity of the stress and strain fields. However, an excellent compromise between the data and the predictive model is noticed at frequencies higher than $90 \mathrm{~Hz}$.

The error between the experimental and the predicted model results are presented in Figure 12. It can be outlined that the errors increase at low frequencies. Below, we will present the results at frequencies higher than $10 \mathrm{~Hz}$ where the average error is lower than $12 \%$.

By analogy, Figure 13 depicts the results of comparison between the experimental complex modulus results and the predictive values in the case of the 'bad-blended' asphalt (Mix 2 ). It can be seen that the predictive micromechanical model gives a good estimation of the complex modulus in a wide range of frequencies $10-5,00,000 \mathrm{~Hz}$ and the maximal average error was lower than 14\% (Figure 14).

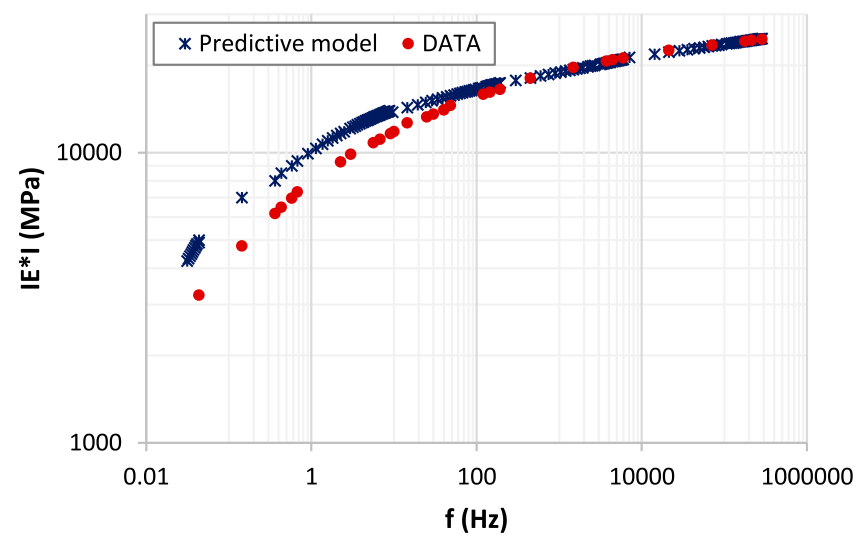

Figure 11. Comparison of the experimental and numerical master curves (case of Mix 1, Well-blended) at $T=15^{\circ} \mathrm{C}$. 


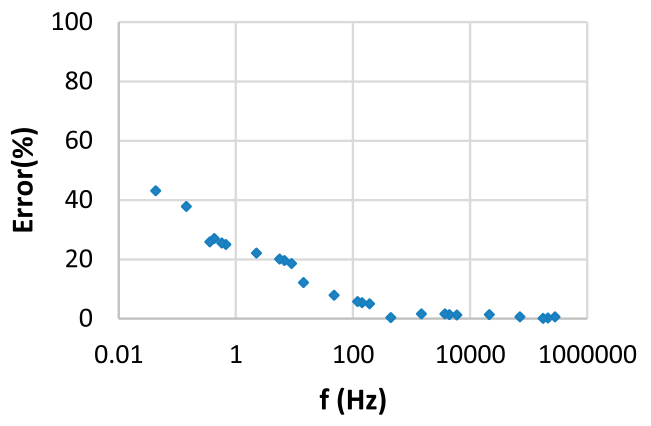

Figure 12. Evolution of the error between experimental complex modulus and predictive model (Case of Mix 1, well-blended).

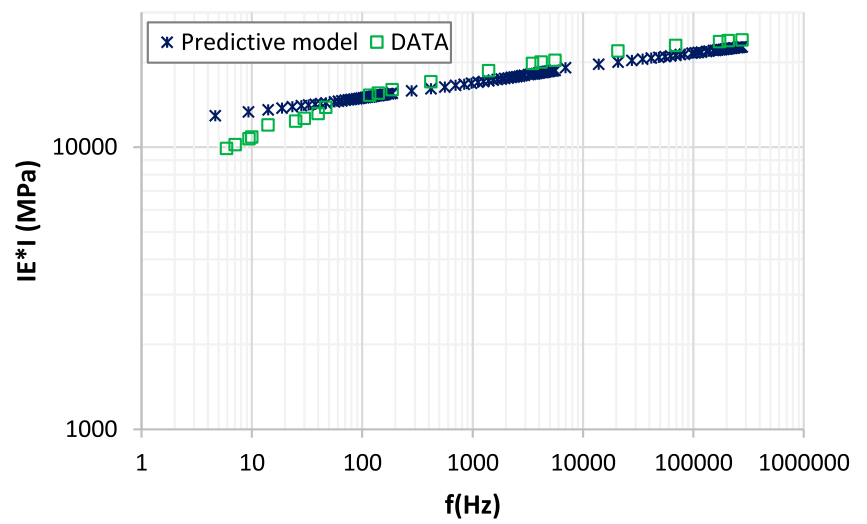

Figure 13. Comparison of the experimental and numerical master curves (Case of Mix 2, Bad-blended) at $T=15^{\circ} \mathrm{C}$.

The comparison of the complex modulus results obtained by the predictive micromechanical model with the experimental reference data is depicted in Figure 15 for both 'Mix 1' and 'Mix 2' cases. It can be shown that the results are in general coherent with the experimental ones. As can be seen, the complex modulus of the recycled 'bad- blended' asphalt (Mix 2) is lower than the complex modulus of the 'well-blended' asphalt (Mix 1). This finding clearly highlights the effect of the homogeneity level between the virgin and the RAP binders on the viscoelastic properties of the recycled asphalt mixture. This finding was also confirmed previously by the experimental approach. On the other hand, the comparison with the reference asphalt shows that a similar tendency is noticed for the three mixtures and that the Mix 1 exhibits higher rigidity than the reference case although the high RAP content.

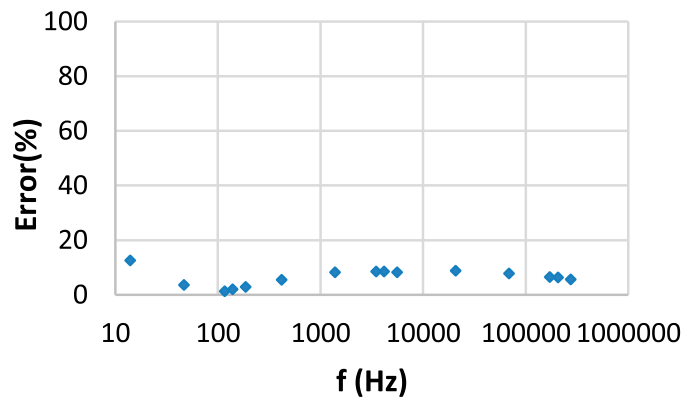

Figure 14. Evolution of the error between experimental complex modulus and predictive model (Case of Mix 2, bad-blended).

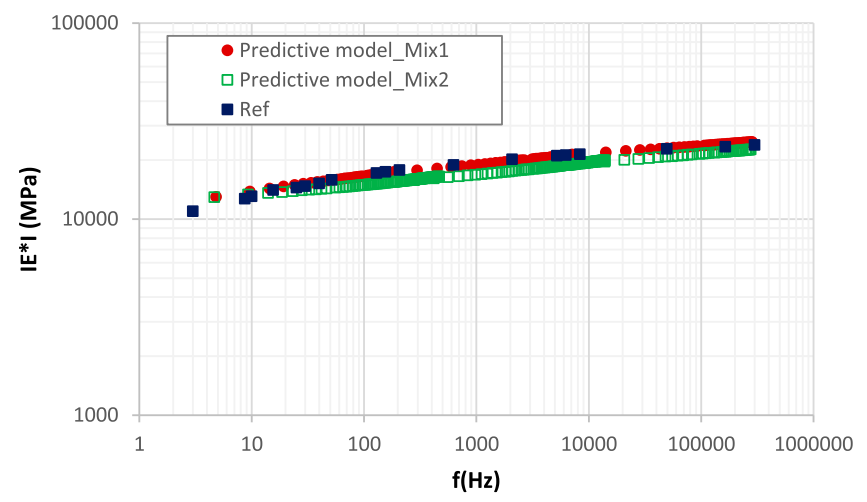

Figure 15. Comparison of the predictive model (Mix 1 well-blended, Mix 2 badblended) and the reference case (master curves).

\section{Conclusions}

In this paper, the performance of a recycled asphalt mixture composed of 70\% RAP was experimentally tested. According the blending level of the RAP binder into the virgin one, two cases of recycled asphalt mixtures were considered ('wellblending' and 'bad-blending'). The complex modulus of the mixes were determined experimentally and compared to the reference asphalt results. Furthermore, a micromechanical model based on the generalised self-consistent scheme was developed in order to predict the complex modulus of the recycled asphalt based on the knowledge of the mechanical properties of the different phases.

Given the obtained results, different conclusions can be drawn:

- From an experimental point of view, the comparison of the recycled mixtures with the reference asphalt has demonstrated that the 70\%-RAP recycled asphalt exhibits similar performances than the reference one with a better behaviour of the 'well-blended' recycled asphalt in comparison with the 'bad-blended' one. It has been shown that the error recorded for the complex modulus estimation at $T=15^{\circ} \mathrm{C}$ and $f=$ $10 \mathrm{~Hz}$, is about $18 \%$ for the 'bad-blended' mixture versus $9 \%$ for the 'well-blended' asphalt when compared to the reference concrete.

- The confrontation of the experimental Data with the result derived from the micromechanical model has shown good approximations for the prediction of the complex modulus of the recycled asphalt concrete in both 'well-blended' and 'bad-blended' cases. The 'bad-blended' recycled asphalt has shown an underestimation of the predicted complex modulus in comparison with the 'well-blended' mixture. This finding is very coherent with the aforementioned experimental results.

In summary, the different findings have proved that the processing condition is a key parameter, which can play a crucial role in controlling the mechanical performance of the recycled asphalt. In addition, the micromechanical approach was validated in the viscoelastic case, and can thereby constitute an effective numerical tool for the prediction of the mechanical behaviour of other heterogeneous viscoelastic materials. 
In the future, it would be interesting to further investigate the effect of the microstructure, the homogeneity level between the virgin and the RAP binders, on the long-term mechanical behaviour such as fatigue and rutting performances.

\section{Disclosure statement}

No potential conflict of interest was reported by the authors.

\section{References}

Aigner, E., Lackner, R., and Eberhardsteiner, J., 2012. Multiscale viscoelastic-viscoplastic model for the prediction of permanent deformation in flexible pavements. International Journal for Multiscale Computational Engineering, 10, 615-634.

Alam, S.Y. and Hammoum, F., 2015. Viscoelastic properties of asphalt concrete using micromechanical self-consistent model. Archives of Civil and Mechanical Engineering, 15, 272-285.

Bazzaz, M., Darabi, M.K., and Little, D.N., 2018. A straightforward procedure to characterize nonlinear viscoelastic response of asphalt concrete at high temperatures. Journal of the Transportation Research Board, No. 18-03704.

Bhusal, S. and Wen, H., 2013. Evaluating recycled concrete aggregate as hot mix asphalt aggregate. Advances in Civil Engineering Materials, 2 (1), 252-265.

Buttlar, W.G., et al., 1999. Understanding asphalt mastic behavior through micromechanics. Transportation Research Record: Journal of the Transportation Research Board, 1681, 157-169.

Buttlar, W.G. and Roque, R., 1996. Evaluation of empirical and theoretical models to determine asphalt mixture stiffnesses at low temperatures. Journal of Association of Asphalt Paving Technologists, 65, 99-130.

Button, J.W., Little, D.N., and Estakhri, C.K., 1994. Hot in-place recycling of asphalt concrete. In: J.M. Sussman, ed. National cooperative research program synthesis of highway practice 193, transportation research board. Washington: Joseph Martin Sussman, 33-34.

Daniel, J.S., et al., 2018. Comparison of asphalt mixture specimen fabrication methods and binder tests for cracking evaluation of field mixtures. Road Materials and Pavement Design, 20, 1059-1075.

Di Benedetto, H., et al., 2004. Linear viscoelastic behavior of bituminous materials: from binders to mixes. Road Materials and Pavement Design, 5, 163-202.

Di Benedetto, H. and Des Croix, P., 1996. Binder-mix rheology: limits of linear domain, nonlinear behaviour. In: The Eurasphalt and Eurobitume Congress.

Eddhahak-Ouni, A., et al., 2012. On a laboratory experimental protocol for qualitative characterization of high rate recycled asphalt mixtures. In: The 5th Eurasphalt \& Eurobitume Congress. Istanbul.

Eddhahak-Ouni, A., Vandamme, M., and Vu, V.T., 2015. Micromechanical contribution for the prediction of the viscoelastic properties of high rate recycled asphalt and influence of the level blending. Archives of Civil and Mechanical Engineering, 15, 1037-1045.

European Standard NF EN 12697-26. Bituminous mixtures: test methods for hot mix asphalt. Part 26: stiffness modulus.

European Standard NF EN 12697-3. Bituminous mixtures: test methods for hot mix asphalt. Part 3 Bitumen recovery: Rotary evaporator.

European Standard NF EN 12697-31. Bituminous mixtures: test methods for hot mix asphalt. Part 31: Specimen preparation by gyratory compactor.

Fakhari Tehrani, F., et al., 2016. Micromechanical modelling of bituminous materials' complex modulus at different length scales. International Journal of Pavement Engineering, 19 (8), 685-696.
Franken, L. and Vanelstraete, A., 1995. Relation between mix stiffness and binder complex modulus, the rheology of bituminous binders. In: The European Workshop. Brussels.

Hervé, E. and Zaoui, A., 1993. n-Layered inclusion based micromechanical modelling. International Journal of Engineering Science, 31, 1-10.

Huet, C., 1999. Coupled size and boundary-condition effects in viscoelastic heterogeneous and composite bodies. Mechanics of Materials, 31, 787829.

Islam, M., et al., 2014. Effects of reclaimed asphalt pavement on hot-mix asphalt. Advances in Civil Engineering Materials, 3 (1), 291-307.

Kaseer, F., et al., 2018. Performance of asphalt mixtures with high recycled materials content and recycling agents. International Journal of Pavement Engineering, 3 (4), 261-268.

Kim, Y.R. and Little, D.N., 2004. Linear viscoelastic analysis of asphalt mastics. Journal of Materials in Civil Engineering, 16, 122-132.

Lachihab, A., 2004. A numerical model for the two-phase composites matrix-rigid inclusions: application to the determination of the elastic and fatigue properties of the Bituminous materials. Thesis (PhD). Ecole Nationale des Ponts et Chaussées.

Little, D.N., Holmgreen, R.J., and Epps, J.A., 1981. Effect of recycling agents on the structural performance of recycled asphalt concrete materials. Proceedings of the Association of Asphalt Paving Technologists, 50, 32-63.

Moutier, F., 1991. Etude statistique de l'effet de la composition des enrobés bitumineux sur leur comportement en fatigue et leur module complexe. Bulletin de liaison des laboratoires des ponts et chaussées, 172, 33-41.

Navaro, J., 2011. Cinétique de mélange des enrobés recyclés et influence sur les performances mécaniques. Thesis ( $\mathrm{PhD})$. Ecole Nationale Supérieure d'Arts et Métiers.

Riccardi, C., et al., 2017. A novel back-calculation approach for determining the rheological properties of RAP binder. Road Materials and Pavement Design, 18, 2164-7402.

Sabahfer, N. and Hossain, M., 2015. Effect of fractionation of reclaimed asphalt pavement on properties of superpave mixtures with reclaimed asphalt pavement. Advances in Civil Engineering Materials, 4 (1), 47-60.

Saha, D.C. and Mandal, J.N., 2018. Performance of reclaimed asphalt pavement reinforced with Bamboo geogrid and Bamboo geocell. International Journal of Pavement Engineering, 1-12. doi:10.1080/ 10298436.2018.1502432.

Shashidhar, N. and Shenoy, A., 2002. On using micromechanical models to describe dynamic mechanical behavior of asphalt mastics. Mechanics of Materials, 34, 657-669.

Shell Bitumes, 1991. Techniques et Utilisations.

Underwood, B.S. and Kim, Y.R., 2014. A four phase micro-mechanical model for asphalt mastic modulus. Mechanics of Materials, 75, 13-33.

Vanelstraete, A., et al., 2004. Selection of binders for asphalt mixes with reclaimed asphalt as studied in the paramix project. In: The $3 \mathrm{rd}$ Eurasphalt \& Eurobitume congress. Vienna: Foundation Eurasphalt, 612-623.

Williams, M.L., Landel, R.F., and Ferry, J.D., 1955. The temperature dependence of relaxation mechanisms in amorphous polymers and other glass-forming liquids. Journal of the American Chemical Society, 77 (14), 3701-3707.

XP T 66-065. Determination of the complex module.

$\mathrm{Xu}, \mathrm{Q}$. and Solaimanian, M., 2009. Modelling linear viscoelastic properties of asphalt concrete by the Huet-Sayegh model. International Journal of Pavement Engineering, 10, 401-422.

Yin, H. M., et al., 2008. Assessment of existing micro-mechanical models for asphalt mastics considering viscoelastic effects. Road Materials and Pavement Design, 9, 31-57.

Zaumanis, M., Cavalli, M.C., and Poulikakos, L.D., 2019. How not to design $100 \%$ recycled asphalt mixture using performance-based tests. Road Materials and Pavement Design. doi:10.1080/14680629.2018. 1561381. 


\section{Appendix}

A1. Coefficients Ai, Bi, Fi (Hervé and Zaoui, 1993):

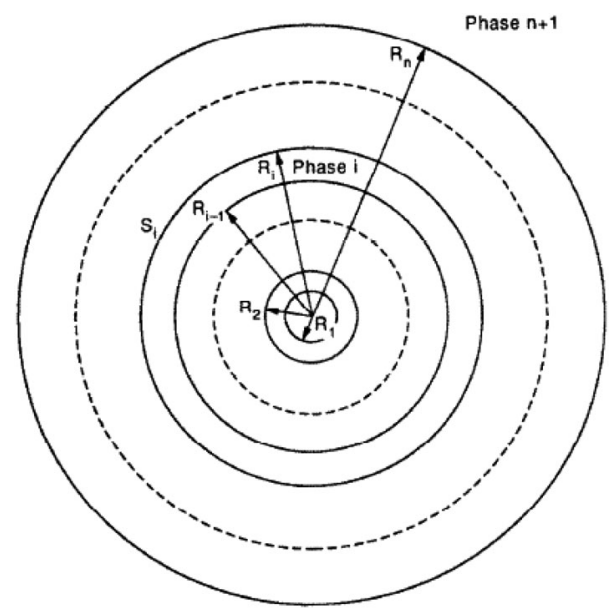

Figure A1. The n-layered spherical inclusion embedded in an infinite matrix (source (Hervé and Zaoui 1993)).

$$
\begin{gathered}
F_{i}=\frac{1}{Q_{11}^{n}} F_{n+1} \\
Q^{(k)}=\prod_{j=1}^{(k)} N^{(j)} \\
N^{(k)}=\frac{1}{3 K_{k+1}+4 \mu_{k+1}}\left(\begin{array}{cc}
3 K_{k}+4 \mu_{k+1} & \frac{4}{R_{k}^{3}}\left(\mu_{k+1}-\mu_{k}\right) \\
3\left(K_{k+1}-K_{k}\right) R_{k}^{3} & 3 K_{k+1}+4 \mu_{k}
\end{array}\right) \\
A_{i}=P_{22}^{(n)} \frac{A_{n+1} \frac{A_{11}^{(n)}}{(n)}-P_{22}^{(n)} P_{21}^{(n)}}{(i-1)} ; \quad i=[1, n+1] \\
B_{i}=-P_{21}^{(n)} \frac{A_{n+1}}{P_{11}^{(n)} P_{22}^{(n)}-P_{12}^{(n)} P_{21}^{(n)}} P^{(i-1)} ; \quad i=[1, n+1] \\
P^{n}=\prod_{i=1}^{n} M^{i}
\end{gathered}
$$

And

$$
\begin{aligned}
\boldsymbol{M}^{(\boldsymbol{k})} & =\frac{1}{5\left(1-\vartheta_{k+1}\right)} \\
& \times\left(\begin{array}{cccc}
\frac{C_{k}}{3} & \frac{R_{k}^{2}\left(3 b_{k}-7 C_{k}\right)}{5\left(1-2 \vartheta_{k}\right)} & \frac{-12 \alpha_{k}}{R_{k}^{5}} & \frac{4\left(f_{k}-27 \alpha_{k}\right)}{15\left(1-2 \vartheta_{k}\right) R_{k}^{3}} \\
0 & \frac{\left(1-2 \vartheta_{k+1}\right) b_{k}}{7\left(1-2 \vartheta_{k}\right)} & \frac{-20\left(1-2 \vartheta_{k+1}\right) \alpha_{k}}{7 R_{k}^{7}} & \frac{-12 \alpha_{k}\left(1-2 \vartheta_{k+1}\right)}{7\left(1-2 \vartheta_{k}\right) R_{k}^{5}} \\
\frac{R_{k}^{5} \alpha_{k}}{2} & \frac{R_{k}^{7}\left(2 a_{k}-14 \alpha_{k}\right)}{70\left(1-2 \vartheta_{k}\right)} & \frac{d_{k}}{7} & \frac{R_{k}^{2}\left[105\left(1-\vartheta_{k+1}\right)+12 \alpha_{k}\left(7-10 \vartheta_{k+1}\right)-7 e_{k}\right.}{35\left(1-2 \vartheta_{k}\right)} \\
-\frac{5}{6}\left(1-2 \vartheta_{k+1}\right) \alpha_{k} R_{k}^{3} & \frac{7\left(1-2 \vartheta_{k+1}\right) \alpha_{k} R_{k}^{5}}{2\left(1-2 \vartheta_{k}\right)} & 0 & \frac{e_{k}\left(1-2 \vartheta_{k+1}\right)}{3\left(1-2 \vartheta_{k}\right)}
\end{array}\right)
\end{aligned}
$$


With:

$$
\begin{aligned}
a_{k} & =\left(7+5 \vartheta_{k}\right)\left(7-10 \vartheta_{k+1}\right) \frac{\mu_{k}}{\mu_{k+1}}-\left(7-10 \vartheta_{k}\right)\left(7+5 \vartheta_{k+1}\right) \\
b_{k} & =4\left(7+10 \vartheta_{k}\right)+\left(7+5 \vartheta_{k}\right) \frac{\mu_{k}}{\mu_{k+1}} \\
c_{k} & =\left(7-5 \vartheta_{k+1}\right)+2\left(4+5 \vartheta_{k+1}\right) \frac{\mu_{k}}{\mu_{k+1}} \\
d_{k} & =\left(7-5 \vartheta_{k+1}\right)+4\left(7+10 \vartheta_{k+1}\right) \frac{\mu_{k}}{\mu_{k+1}} \\
e_{k} & =2\left(4-5 \vartheta_{k}\right)+\left(7+5 \vartheta_{k}\right) \frac{\mu_{k}}{\mu_{k+1}} \\
\alpha_{k} & =\frac{\mu_{k}}{\mu_{k+1}}-1
\end{aligned}
$$

\section{A.2. Effective shear modulus solution according to the $(n+1)$ - phase model}

With

$$
A\left(\frac{\mu^{\text {hom }}}{\mu_{n}}\right)^{2}+B\left(\frac{\mu^{\text {hom }}}{\mu_{n}}\right)+C=0
$$

$$
\begin{aligned}
A= & 4 R_{n}^{10}\left(1-2 \vartheta_{n}\right)\left(7-10 \vartheta_{n}\right) Z_{12}+20 R_{n}^{7}\left(7-12 \vartheta_{n}+8 \vartheta_{n}^{2}\right) Z_{42} \\
& +12 R_{n}^{5}\left(1-2 \vartheta_{n}\right)\left(Z_{14}-7 Z_{23}\right)+20 R_{n}^{3}\left(1-2 \vartheta_{n}\right)^{2} Z_{13} \\
& +16\left(4-5 \vartheta_{n}\right)\left(1-2 \vartheta_{n}\right) Z_{43} \\
B= & 3 R_{n}^{10}\left(1-2 \vartheta_{n}\right)\left(15 \vartheta_{n}-7\right) Z_{12}+60 R_{n}^{7}\left(\vartheta_{n}-3\right) \vartheta_{n} Z_{42} \\
& -24 R_{n}^{5}\left(1-2 \vartheta_{n}\right)\left(Z_{14}-7 Z_{23}\right)-40 R_{n}^{3}\left(1-2 \vartheta_{n}\right)^{2} Z_{13} \\
& -8\left(4-5 \vartheta_{n}\right)\left(1-2 \vartheta_{n}\right) Z_{43} \\
C= & -4 R_{n}^{10}\left(1-2 \vartheta_{n}\right)\left(5 \vartheta_{n}+7\right) Z_{12}+10 R_{n}^{7}\left(7-\vartheta_{n}^{2}\right) Z_{42} \\
& +12 R_{n}^{5}\left(1-2 \vartheta_{n}\right)\left(Z_{14}-7 Z_{23}\right)+20 R_{n}^{3}\left(1-2 \vartheta_{n}\right)^{2} Z_{13} \\
& -8\left(7-5 \vartheta_{n}\right)\left(1-2 \vartheta_{n}\right) Z_{43} \\
&
\end{aligned}
$$

Where

$$
Z_{\alpha \beta}=P_{\alpha 1}^{(n-1)} P_{\beta 2}^{(n-1)}-P_{\beta 1}^{(n-1)} P_{\alpha 2}^{(n-1)} ; \alpha, \beta \in[1.4]
$$

